\title{
Risk of ketoacidosis in children at the time of diabetes mellitus diagnosis by primary caregiver status: a population-based retrospective cohort study
}

\author{
Meranda Nakhla MD MSc, Elham Rahme PhD, Marc Simard MSc, Isabelle Larocque MSc, Laurent Legault MD, \\ Patricia Li MD MSc
}

n Cite as: CMAJ 2018 April 9;190:E416-21. doi: 10.1503/cmaj.170676

See related article at www.cmaj.ca/lookup/doi/10.1503/cmaj.180220

\begin{abstract}
BACKGROUND: Diabetic ketoacidosis is the leading cause of death among children with type 1 diabetes mellitus, and is an avoidable complication at first-time diagnosis of diabetes. Because having a usual provider of primary care is important in improving health outcomes for children, we tested the association between having a usual provider of care and risk of diabetic ketoacidosis at onset of diabetes.
\end{abstract}

METHODS: Using linked health administrative data for the province of Quebec, we conducted a population-based retrospective cohort study of children aged 1-17 years in whom diabetes was diag- nosed from 2006 to 2015. We estimated adjusted risk ratios (RRs) for an episode of diabetic ketoacidosis at the time of diabetes diagnosis in relation to usual provider of care (family physician, pediatrician or none) using Poisson regression models with robust error variance.

RESULTS: We identified 3704 new cases of diabetes in Quebec children from 2006 to 2015 . Of these, 996 (26.9\%) presented with diabetic ketoacidosis. A decreased risk of this complication was associated with having a usual provider of care; the association was stronger with increasing age, reaching statistical significance among those aged $12-17$ years. Within this age group, those who had a family physician or a pediatrician were $31 \%$ less likely (adjusted RR 0.69, 95\% confidence interval [Cl] $0.56-0.85$ ) or $38 \%$ less likely (adjusted RR 0.62, 95\% Cl 0.45-0.86), respectively, to present with diabetic ketoacidosis, relative to those without a usual provider of care.

INTERPRETATION: For children with newly diagnosed diabetes, having a usual provider of care appears to be important in decreasing the risk of diabetic ketoacidosis at the time of diabetes diagnosis. Our results provide further evidence concerning the need for initiatives that promote access to primary care for children.
$\mathrm{T}$ ype 1 diabetes mellitus is one of the most common chronic diseases of childhood, with a global incidence that is increasing by $3 \%-5 \%$ per year in children. ${ }^{1,2}$ The annual incidence of type 1 diabetes in Quebec is 30 per 100000 population, similar to that of other Canadian provinces and among the highest in the world. ${ }^{3,4}$ Diagnosis of diabetes is preceded by a variable period of symptoms that include polyuria, polydipsia, weight loss, fatigue and polyphagia. If the condition is left untreated, between 19\% (Ontario) and 40\% (United States) of North American children will present at first-time diagnosis with diabetic ketoacidosis (DKA), a largely preventable life-threatening complication. ${ }^{5,6}$ DKA is the most common cause of death among children with type 1 diabetes and is associated with an increased risk of cerebral edema and cognitive deficits. ${ }^{7-9}$ The costs of 1 DKA-related hospital admission are high, ranging from US\$4125 to US\$11 196, in addition to the familial and societal costs associated with missed work and school days. ${ }^{10}$ Because symptoms exist before the onset of DKA, a delay in the diagnosis and treatment of diabetes can be a risk factor for DKA. ${ }^{11}$ Other factors, such as younger age $(<5 \mathrm{yr})$, lower socioeconomic status and lower parental education, also confer an increased risk of DKA at onset of diabetes. ${ }^{11}$ Despite the availability of universal health care coverage in Canada, a substantial number of children continue to present with DKA at the time of diabetes diagnosis. ${ }^{5}$

Access to high-quality primary care is valuable to child health. Having a usual provider of care has been associated with better 
overall health outcomes because of preventive and early intervention for health problems, continuity of care and improved access to health care services. ${ }^{12,13}$ In the US, children on Medicaid with established type 1 diabetes were 70\% less likely to have an episode of DKA if they had high relative to low continuity of primary care. ${ }^{14}$ Currently, about 4 million to 5 million Canadians do not have a usual provider of care. ${ }^{15}$ The prevention of DKA at diabetes diagnosis is dependent on time-sensitive care; there is limited evidence on whether having a usual provider of care can contribute to reducing the risk of DKA at diabetes onset. ${ }^{16}$ We aimed to fill this important knowledge gap. We hypothesized that children with a usual provider of care would be less likely than those without a usual provider to have a DKA episode at diabetes diagnosis.

\section{Methods}

\section{Study design}

Using multiple linked administrative databases, we conducted a retrospective cohort study of children aged 1-17 years living in Quebec, with diagnosis of diabetes between Apr. 1, 2006, and Mar. 31, 2015. Quebec provides universal coverage for medically necessary health care services for all legal residents of the province.

\section{Data sources and cohort identification}

We used health administrative data for all individuals with diabetes available at the Institut national de santé publique du Québec through its chronic disease surveillance program. ${ }^{17}$ We used the following databases: Registered Persons Database (patient demographic characteristics) and Physician Service Claims Database (remunerated physician services across all clinical settings), both maintained by the Régie de l'assurance maladie du Québec (RAMQ), and the Hospital Discharge Database (MED-ECHO), maintained by the Ministère de la Santé et des Services sociaux. The RAMQ linked these databases using a unique encoded identifier. ${ }^{18}$

We used the Canadian Chronic Disease Surveillance System's validated definition of diabetes (specificity 99.9\%, sensitivity 94\%) to identify all children with this diagnosis during the study period. This definition requires 1 admission to hospital or 2 physician visit claims with a diabetes code, within a 2-year period. ${ }^{19}$ The date of diagnosis was defined as either the first admission to hospital or the first physician claim coded for diabetes. The algorithm does not distinguish between type 1 and type 2 diabetes; however, most (about 95\%) Canadian children and youth with a diagnosis of diabetes have the type 1 form. ${ }^{20}$ We excluded patients with invalid health insurance numbers.

\section{Outcome}

The primary outcome was any DKA episode that took place at the time diabetes was diagnosed, identified in terms of a principal or secondary diagnosis of DKA from physician billings (Quebec version of the International Classification of Diseases, 9th revision, codes 250.1-250.2) or from MED-ECHO hospital data (enhanced Canadian version of the International Statistical Classification of Diseases and Related Health Problems, 10th revision, codes E10.10-E14.10 and E10.12-E14.12) occurring within 3 days of the date of a diabetes diagnosis. ${ }^{21-23}$ We chose a 3-day window because a patient with DKA within this reasonably short period after diagnosis likely had DKA at the time of diagnosis.

\section{Exposure to usual provider of care}

We defined the usual provider of care as the physician who provided routine primary care and was part of the child's medical home (i.e., a delivery model whereby a physician provides coordinated, continuous and comprehensive primary care) or as the primary care physician from whom the child sought care most often and who may have also provided aspects of the medical home. ${ }^{13,24,25}$ For each patient, we examined all physician claims made in the 2 years and up to 7 days before the date of diabetes diagnosis (index date). Although children younger than 2 years had a shorter exposure period, they would have had more opportunities for physician encounters, given there are at least 6 recommended preventive visits during these early years (www.rourkebabyrecord.ca/). We defined the exposure period as ending up to 7 days before the index date, to minimize misclassifying children who had several visits in a short period before diagnosis as having a usual provider of care; we felt that this pattern of visits would not truly indicate a regular source of primary care. In Quebec, primary care for children is mainly delivered by family physicians and pediatricians.

To identify a child's usual provider of care, we adapted an algorithm for the pediatric population that was previously developed using Quebec health administrative data. ${ }^{24}$ Our algorithm assigned a usual provider of care according to the following hierarchy: the usual provider of care billed codes that identified the patient as being enrolled into a practice (available to family physicians); the usual provider of care billed codes used for monitoring routine growth and development (available to pediatricians); or, on the basis of all primary health care visits, the usual provider of care billed at least 2 visits and had provided most of these visits. In the case of a tie for the third step of the algorithm, we assigned a family physician as the usual provider of care if 2 complete annual medical exams were billed by a family physician; otherwise, a pediatrician was assigned as the usual provider of care. Patients who did not fulfill any of these criteria were assigned to the category "no usual provider of care" (see complete algorithm in Appendix 1, available at www.cmaj.ca/lookup/suppl/doi:10.1503/ cmaj.170676/-/DC1).

\section{Covariables}

The covariables were sex, age, combined material and social deprivation index (a proxy for socioeconomic status) and rurality status at diagnosis. We categorized participants into the following age groups: preschool (1-4 yr), school age (5-11 yr) and adolescence ( 12 to $\leq 17 \mathrm{yr}$ ). We determined socioeconomic status using a validated area-based deprivation index, whereby each individual was assigned a material and a social deprivation quintile ( $1=$ most privileged, $5=$ most deprived). ${ }^{26}$ The material and social quintiles were combined, and individuals were grouped into 3 categories: least deprived, moderately deprived and most deprived. We defined rurality status using the Census Metropolitan Areas and Census Agglomeration Influenced Zones developed by Statistics Canada. ${ }^{27}$ There were 3 rurality categories: urban (population > 100000 ), small cities (population 10000-100000) and rural 
(population < 10000 ). We assigned deprivation index and rurality status according to the individual's residential postal code.

\section{Statistical analysis}

We used $t$ tests to compare continuous variables and the Pearson $\chi^{2}$ test for categorical variables. We used multivariable Poisson regression analysis with robust error variance to model the relation between having a usual provider of care and DKA at diabetes diagnosis and to obtain an adjusted relative risk (RR). The final model included all of the covariables selected a priori. Because the association between usual provider of care and DKA could be modified by age (whereby it may be more difficult to diagnose diabetes in younger children despite their having a usual provider of care), we added an interaction term for age group and usual provider of care. We included in the analysis individuals with missing variables.

We conducted a sensitivity analysis using a different definition for usual provider of care: in step 3 of the algorithm, patients with at least 2 visits with a pediatrician were assigned as having a pedi- atrician as the usual provider of care, and patients with at least 2 visits with a family physician were assigned as having a family physician as the usual provider of care. We conducted another sensitivity analysis with different definitions for the exposure period (i.e., from $30 \mathrm{~d}$ to up to $1 \mathrm{~d}$ before the index date).

We performed statistical analyses with SAS software, version 9.4 (SAS Institute). The statistical tests were 2 -sided with significance at $p<0.05$.

\section{Ethics approval}

This study was approved by the Research Ethics Board of the McGill University Health Centre.

\section{Results}

We identified 3704 patients with newly diagnosed diabetes (Table 1). The mean age at diagnosis was 10.1 (standard deviation 4.8) years, and 1944 (52.5\%) were males. Of the overall study

Table 1: : Characteristics of children with and without diabetic ketoacidosis at the time of diagnosis of type 1 diabetes mellitus

\begin{tabular}{|c|c|c|c|c|}
\hline \multirow[b]{2}{*}{ Characteristic } & \multicolumn{3}{|c|}{ Group; no. (\%) of participants* } & \multirow[b]{2}{*}{$p$ value } \\
\hline & Study population & Without DKA & With DKA & \\
\hline Population size & $3704(100.0)$ & 2708 (73.1) & $996(26.9)$ & \\
\hline Age, $y r$, mean \pm SD & $10.1 \pm 4.8$ & $10.3 \pm 4.9$ & $9.3 \pm 4.6$ & $<0.001$ \\
\hline \multicolumn{2}{|l|}{ Age, yr, by category } & & & $<0.001$ \\
\hline $1-4$ & $666(18.0)$ & $476(17.6)$ & $190(19.1)$ & \\
\hline $5-11$ & $1403(37.9)$ & $954(35.2)$ & $449(45.1)$ & \\
\hline $12-17$ & $1635(44.1)$ & $1278(47.2)$ & $357(35.8)$ & \\
\hline \multicolumn{2}{|l|}{ Sex } & & & 0.5 \\
\hline Male & $1944(52.5)$ & $1412(52.1)$ & $532(53.4)$ & \\
\hline Female & $1760(47.5)$ & $1296(47.9)$ & $464(46.6)$ & \\
\hline \multicolumn{2}{|l|}{$\begin{array}{l}\text { Socioeconomic status (social and } \\
\text { material deprivation) } \dagger\end{array}$} & & & 0.1 \\
\hline Least deprived & $1544(43.0)$ & $1154(44.0)$ & $390(40.5)$ & \\
\hline Moderately deprived & $729(20.3)$ & $531(20.2)$ & $198(20.5)$ & \\
\hline Most deprived & $1316(36.7)$ & $940(35.8)$ & $376(39.0)$ & \\
\hline \multicolumn{2}{|l|}{ Rurality $\ddagger$} & & & 0.04 \\
\hline Urban (population > 100 000) & $2438(66.1)$ & $1787(66.2)$ & $651(65.7)$ & \\
\hline Small cities (population $10000-100000$ ) & $477(12.9)$ & $328(12.2)$ & $149(15.0)$ & \\
\hline Rural (population < 10000 ) & $775(21.0)$ & $584(21.6)$ & $191(19.3)$ & \\
\hline \multicolumn{2}{|l|}{ Usual provider of care } & & & 0.004 \\
\hline None & $1527(41.2)$ & $1073(39.6)$ & $454(45.6)$ & \\
\hline Family physician & $1437(38.8)$ & $1084(40.0)$ & $353(35.4)$ & \\
\hline Pediatrician & $740(20.0)$ & $551(20.3)$ & $189(19.0)$ & \\
\hline \multicolumn{5}{|c|}{$\begin{array}{l}\text { Note: } \mathrm{DKA}=\text { diabetic ketoacidosis, } \mathrm{SD}=\text { standard deviation. } \\
\text { "Except where indicated otherwise. } \\
\text { † Missing socioeconomic status for } 115 \text { of the study population, consisting of } 83 \text { without and } 32 \text { with DKA. For this variable, social and material quintiles were } \\
\text { combined into a } 5 \times 5 \text { table, and the } 25 \text { combined categories were grouped into } 3 \text { categories: least deprived, moderately deprived and most deprived. } \\
\text { † Missing rurality for } 14 \text { of the study population, consisting of } 9 \text { without and } 5 \text { with DKA. }\end{array}$} \\
\hline
\end{tabular}


population, 2177 (58.8\%) had a usual provider of care before diagnosis of diabetes, and 996 (26.9\%) presented with DKA at the time of diabetes onset. By age group, the rate of DKA was $28.5 \%(190 / 666)$ among those $1-4$ years old, $32.0 \%$ (449/1403) among those 5-11 years old and $21.8 \%$ (357/1635) among those $12-17$ years old.

The interaction term between age group and usual provider of care was significant, and was therefore included in the final multivariable model (Table 2 and Appendix 2, available at www.cmaj.ca/ lookup/suppl/doi:10.1503/cmaj.170676/-/DC1). Having a usual provider of care was associated with a decreased risk of DKA; however, while the association became stronger with increasing age, it was statistically significant only for those 12-17 years of age (Table 2). Those receiving care from a family physician or a pediatrician were $31 \%$ less likely (adjusted RR 0.69, 95\% confidence interval [CI] 0.56 0.85 ) or $38 \%$ less likely (adjusted RR $0.62,95 \% \mathrm{Cl} 0.45-0.86$ ) to present with DKA, relative to those without a usual provider of care (Table 2). Appendix 2 presents the interaction term showing the effect of age classified by usual provider of care, whereby within each category, those less than 12 years old were more at risk of DKA than those 12-17 years old.

In terms of social and material deprivation, children from the most deprived category were $14 \%$ more likely to have a DKA episode than those in the least deprived category (adjusted RR 1.14, 95\% Cl 1.01-1.28). In terms of rurality, those living in small cities were $17 \%$ more likely to have a DKA episode than those living in urban areas (adjusted RR 1.17 95\% Cl 1.01-1.35).

\section{Sensitivity analyses}

In the sensitivity analyses, the association between having a usual provider of care and risk of DKA did not change, either when we redefined the algorithm for assigning usual provider of care (whereby in step 3, a pediatrician was assigned as the usual provider of care if there were $\geq 2$ visits with pediatrician or a family physician was assigned if there were $\geq 2$ visits with a family physician) or when we varied the exposure period (from $30 \mathrm{~d}$, $14 \mathrm{~d}$ and $1 \mathrm{~d}$ up to the index date) (Appendix 3, available at www. cmaj.ca/lookup/suppl/doi:10.1503/cmaj.170676/-/DC1).

\section{Interpretation}

In this population-based study, more than $25 \%$ of children presented with DKA at the time of diabetes onset. The risk of DKA at diabetes onset increased with younger age, living in smaller cities, and greater social and material deprivation. Having a usual provider of care was associated with a reduced risk of DKA at diabetes onset, but this protection reached statistical significance only among those 12-17 years of age. Adolescents who had a family physician or pediatrician were $31 \%$ less likely or $38 \%$ less likely, respectively, to present with DKA relative to adolescents without a usual provider of care.

Previous studies have examined health service utilization in the period leading up to diagnosis. ${ }^{5,16,28} \mathrm{~A}$ single-centre survey in the US found no difference in access to primary care between children who presented with DKA and those who did not; however, this result may have been attributable to the small sample size $(n=$ 61). ${ }^{16} \mathrm{~A}$ population-based cohort study in Canada found that, rela- tive to children who did not have DKA, those who presented with DKA were more likely to have had at least 1 medical visit in the week preceding the diagnosis of diabetes. ${ }^{5}$ Similarly, a retrospective chart audit in New Zealand showed that children who presented with DKA were more likely to have had 1 or more primary care visits in the month preceding diagnosis. ${ }^{28}$ Although the latter 2 studies did not specifically measure access to primary care, they do suggest that the quality of primary care encounters is an important factor in decreasing DKA risk. Our population-based study adds to this literature, suggesting that having a usual provider of care is an important factor in mitigating DKA risk.

Table 2: Crude proportions and adjusted relative risk of diabetic ketoacidosis at diabetes diagnosis

\begin{tabular}{|c|c|c|}
\hline Covariable & $\begin{array}{c}\text { No. }(\%) \text { of patients } \\
\text { with DKA, } \\
\text { by characteristic }\end{array}$ & $\begin{array}{c}\text { Adjusted RR } \\
(95 \% \mathrm{Cl})^{\star}\end{array}$ \\
\hline \multicolumn{3}{|l|}{ Usual provider of care $†$} \\
\hline Age 1-4 yr & $190 / 666(28.5)$ & \\
\hline None & $33 / 114(29.0)$ & 1.00 (ref) \\
\hline Family physician & $99 / 337(29.4)$ & $1.01(0.73-1.41)$ \\
\hline Pediatrician & $58 / 215(27.0)$ & $0.93(0.65-1.34)$ \\
\hline Age 5-11 yr & $449 / 1403(32.0)$ & \\
\hline None & $206 / 589(35.0)$ & 1.00 (ref) \\
\hline Family physician & $147 / 505(29.1)$ & $0.84(0.71-1.00)$ \\
\hline Pediatrician & $96 / 309(31.1)$ & $0.89(0.73-1.09)$ \\
\hline Age $12-17 y r$ & $357 / 1635(21.8)$ & \\
\hline None & $215 / 824(26.1)$ & 1.00 (ref) \\
\hline Family physician & $107 / 595(18.0)$ & $0.69(0.56-0.85)$ \\
\hline Pediatrician & $35 / 216(16.2)$ & $0.62(0.45-0.86)$ \\
\hline \multicolumn{3}{|l|}{ Sex } \\
\hline Female & $464 / 1760(26.4)$ & 1.00 (ref) \\
\hline Male & $532 / 1944(27.4)$ & $1.02(0.92-1.14)$ \\
\hline \multicolumn{3}{|l|}{ Socioeconomic status $\ddagger$} \\
\hline Least deprived & $390 / 1544(25.3)$ & 1.00 (ref) \\
\hline Moderately deprived & $198 / 729(27.2)$ & $1.10(0.95-1.27)$ \\
\hline Most deprived & $376 / 1316(28.6)$ & $1.14(1.01-1.28)$ \\
\hline \multicolumn{3}{|l|}{ Rurality } \\
\hline $\begin{array}{l}\text { Urban (population } \\
>100000 \text { ) }\end{array}$ & $651 / 2438(26.7)$ & 1.00 (ref) \\
\hline $\begin{array}{l}\text { Small cities (population } \\
10000-100000)\end{array}$ & $149 / 477(31.2)$ & $1.17(1.01-1.35)$ \\
\hline Rural (population < 10000) & $191 / 775(24.6)$ & $0.89(0.77-1.02)$ \\
\hline
\end{tabular}

Note: $\mathrm{Cl}=$ confidence interval, $\mathrm{DKA}=$ diabetic ketoacidosis, $\mathrm{ref}=$ reference value, $\mathrm{RR}=$ relative risk.

*Adjusted for usual provider of care, age group, usual provider of care $\times$ age group (interaction term), sex, socioeconomic status and rurality.

†Results for the interaction term presented in this table show the effect of usual provider of care $\times$ age. For example, among those 12-17 years old, having a family physician or pediatrician reduced the risk of DKA. The interaction terms for the effect of usual provider of care $\times$ age are provided in Appendix 2 (available at www.cmaj.ca/ lookup/suppl/doi:10.1503/cmaj.170676/-/DC1).

†Social and material deprivation. 
Similar to our findings, studies in the general pediatrics literature have shown an association between having a usual provider of care and decreased use of acute health services (i.e., hospital admissions, emergency department visits). ${ }^{12,29,30}$ Several mechanisms may explain the relation between having a usual provider of care and presence of DKA at diabetes onset. These include the beneficial effects of continuous primary care, whereby the provider has background knowledge of a child's baseline health status and would be more alert to new symptoms; the beneficial effects of preventive care, whereby parents are counselled during well-child care visits about general health and are told whom to contact in case of illness; and the beneficial effects of the underlying physician-patient relationship, which may influence families' health-seeking behaviours, with parents being more willing to seek medical help from their usual provider of care for nonemergent issues. ${ }^{12,31}$ As a result, the dynamics that result from having a usual provider of care may contribute to more timely access to the health care system, thus decreasing the diagnostic delay and prompting early institution of treatment.

Among younger children, having a usual provider of care may not be protective against DKA for several reasons; for example, the classic symptoms of diabetes may not be obvious, ${ }^{32}$ which may result in a delay in seeking health care (whether or not there is a diagnosis), and younger children may have less well-developed compensatory mechanisms, which could result in faster development of acidosis and dehydration. In previous studies, children under 3 years of age were more likely to have at least 1 medical encounter within the 4 weeks preceding a diagnosis of diabetes and were more likely to be given an alternative diagnosis, relative to children in older age groups. ${ }^{5,32}$ Increasing public or physician awareness of the symptoms of diabetes in this age group may mitigate the risk of DKA in younger children. ${ }^{33}$

That living in small cities was a risk factor contrasts with a previous European study, which found no association between rural-urban status and DKA risk. ${ }^{34}$ The distribution of physician resources and access to health care may differ across geographic settings, which could explain our observations; however, this potential association should be explored further. ${ }^{35}$ As described in other studies, we found that deprivation was associated with an increased DKA risk at diabetes onset. ${ }^{5}$ Possible drivers of this association include lower parental education and hence decreased awareness of symptoms. ${ }^{36,37}$

\section{Limitations}

Although our study included data for all Quebec children and youth with universal health insurance, there were some limitations. The mechanism underlying the observed association between having a usual provider of care and reduced risk of DKA could not be fully elucidated with administrative data. For example, we could not measure characteristics of the patient-physician relationship, including the quality, accessibility and comprehensiveness of care. We also could not verify the classification of usual provider of care, although we conducted sensitivity analyses to investigate misclassification bias. In addition, similar algorithms based on the primary care provider who provided the most visits have been applied to describe regular providers of primary care for children in Ontario. ${ }^{38,39}$ There may have been cases in our study in which a child had not seen the usual provider of care in the 2-year exposure period and was incorrectly classified as not having a usual provider of care. However, the usual provider of care should be up to date with a child's health, especially for rapidly growing and developing children. A minority of Quebec physicians (about $2 \%$ ) are paid by salary, and a small proportion of children may thus have been misclassified as not having a usual provider of care. ${ }^{17,40}$ Although nurse practitioner visits may not appear in the data, these professionals work alongside family physicians who would have billed for enrolling most of these patients.

\section{Conclusion}

Our findings from this large, population-based study suggest that having a usual provider of care was associated with a decreased risk of DKA at diabetes onset and that this association strengthened with increasing age, reaching statistical significance for those aged 12-17 years. Our study provides further evidence for policy-makers about the need to develop and strengthen initiatives that promote primary care for children. Our results highlight the need to develop targeted interventions for children under 12 years of age, including increasing public and physician awareness (through educational campaigns) about the symptoms of diabetes in this age group.

\section{References}

1. Patterson CC, Dahlquist GG, Gyurus E, et al. Incidence trends for childhood type 1 diabetes in Europe during 1989-2003 and predicted new cases 2005-20: a multicentre prospective registration study. Lancet 2009;373:2027-33.

2. Lawrence JM, Imperatore G, Dabelea D, et al. Trends in incidence of type 1 diabetes among non-Hispanic white youth in the US, 2002-2009. Diabetes 2014;63:3938-45.

3. Nakhla M, Rochette L, Rahme E, et al. Trends in diabetes prevalence and incidence in children and youth in Quebec, Canada 2000-2008: a population-based study. Miami: International Society of Pediatric and Adolescent Diabetes; 2011.

4. Fox DA, Islam N, Sutherland J, et al. Type 1 diabetes incidence and prevalence trends in a cohort of Canadian children and youth. Pediatr Diabetes 2017 Aug. 31. [Epub ahead of print].

5. Bui H, To T, Stein R, et al. Is diabetic ketoacidosis at disease onset a result of missed diagnosis? J Pediatr 2010;156:472-7.

6. Dabelea D, Rewers A, Stafford JM, et al. Trends in the prevalence of ketoacidosis at diabetes diagnosis: the SEARCH for diabetes in youth study. Pediatrics 2014; 133:e938-45.

7. Dahlquist G, Kallen B. Mortality in childhood-onset type 1 diabetes: a populationbased study. Diabetes Care 2005;28:2384-7.

8. Lawrence SE, Cummings EA, Gaboury I, et al. Population-based study of incidence and risk factors for cerebral edema in pediatric diabetic ketoacidosis. $J$ Pediatr 2005;146:688-92.

9. Cameron FJ, Scratch SE, Nadebaum C, et al. Neurological consequences of diabetic ketoacidosis at initial presentation of type 1 diabetes in a prospective cohort study of children. Diabetes Care 2014;37:1554-62.

10. Tieder JS, McLeod L, Keren R, et al. Variation in resource use and readmission for diabetic ketoacidosis in children's hospitals. Pediatrics 2013;132:229-36.

11. Usher-Smith JA, Thompson MJ, Sharp SJ, et al. Factors associated with the presence of diabetic ketoacidosis at diagnosis of diabetes in children and young adults: a systematic review. BMJ 2011;343:d4092.

12. Christakis DA, Mell L, Koepsell TD, et al. Association of lower continuity of care with greater risk of emergency department use and hospitalization in children. Pediatrics 2001;107:524-9.

13. Starfield B, Shi L, Macinko J. Contribution of primary care to health systems and health. Milbank Q 2005;83:457-502.

14. Christakis DA, Feudtner C, Pihoker C, et al. Continuity and quality of care for children with diabetes who are covered by Medicaid. Ambul Pediatr 2001;1:99-103.

15. A doctor for every Canadian - better planning for Canada's health human resources. The Canadian Medical Association's brief to the House of Commons Standing Committee on Human Resources, Skills and Social Development and the Status of Persons with Disabilities - addressing existing labour shortages in high-demand occupations. Ottawa: Canadian Medical Association; 2012. 
16. Baldelli L, Flitter B, Pyle L, et al. A survey of youth with new onset type 1 diabetes: opportunities to reduce diabetic ketoacidosis. Pediatr Diabetes 2017;18:547-52.

17. Blais C, Jean S, Sirois C, et al. Quebec Integrated Chronic Disease Surveillance System (QICDSS), an innovative approach. Chronic Dis Inj Can 2014;34:226-35.

18. Rochette L, Emond V. Chronic-disease surveillance in Quebec using administrative file linkage. In: 2014 International Methodology Symposium. Beyond traditional survey taking: adapting to a changing world; 2014 Oct. 29-31; Gatineau (QC). Ottawa (ON): Statistics Canada; 2014.

19. Dart AB, Martens PJ, Sellers EA, et al. Validation of a pediatric diabetes case definition using administrative health data in Manitoba, Canada. Diabetes Care 2011; 34:898-903.

20. Shulman R, Miller FA, Stukel TA, et al. Resources and population served: a description of the Ontario Paediatric Diabetes Network. CMAJ Open 2016;4:E141-6.

21. Shulman R, Stukel TA, Miller FA, et al. Low socioeconomic status is associated with adverse events in children and teens on insulin pumps under a universal access program: a population-based cohort study. BMJ Open Diabetes Res Care 2016;4:e000239.

22. Nakhla M, Rahme E, Simard M, et al. Outcomes associated with a pediatric clinical diabetes network in Ontario: a population-based time-trend analysis. CMAJ Open 2017;5:E586-E93.

23. International statistical classification of diseases and related health problems. 10th revision, Canada. Vol. 1: Tabular list. Ottawa: Canadian Institute for Health Information; 2012. Available: https://www.cihi.ca/en/icd_volume_one_2012_en.pdf (accessed 2015 Mar 28).

24. Provost S, Perez J, Pineault R, et al. An algorithm using administrative data to identify patient attachment to a family physician. Int J Family Med 2015;2015:967230.

25. Aggarwal M, Hutchison B. Toward a primary care strategy for Canada. Ottawa: Canadian Foundation for Healthcare Improvement; 2012.

26. Pampalon R, Raymond $\mathrm{G}$. A deprivation index for health and welfare planning in Quebec. Chronic Dis Can 2000;21:104-13.

27. Pampalon R, Martinez J, Hamel D. Does living in rural areas make a difference for health in Quebec? Health Place 2006;12:421-35.

28. Gunn ER, Albert BB, Hofman PL, et al. Pathways to reduce diabetic ketoacidosis with new onset type 1 diabetes: evidence from a regional pediatric diabetes center: Auckland, New Zealand, 2010 to 2014. Pediatr Diabetes 2017;18:553-8.
29. Brousseau DC, Meurer JR, Isenberg ML, et al. Association between infant continuity of care and pediatric emergency department utilization. Pediatrics 2004;113:738-41.

30. Cecil E, Bottle A, Cowling TE, et al. Primary care access, emergency department visits, and unplanned short hospitalizations in the UK. Pediatrics 2016; 137:e20151492

31. Tom JO, Tseng CW, Davis J, et al. Missed well-child care visits, low continuity of care, and risk of ambulatory care-sensitive hospitalizations in young children. Arch Pediatr Adolesc Med 2010;164:1052-8.

32. Lokulo-Sodipe K, Moon RJ, Edge JA, et al. Identifying targets to reduce the incidence of diabetic ketoacidosis at diagnosis of type 1 diabetes in the UK. Arch Dis Child 2014;99:438-42.

33. Vanelli M, Chiari G, Ghizzoni L, et al. Effectiveness of a prevention program for diabetic ketoacidosis in children. An 8-year study in schools and private practices. Diabetes Care 1999;22:7-9.

34. Komulainen J, Lounamaa R, Knip M, et al. Ketoacidosis at the diagnosis of type 1 (insulin dependent) diabetes mellitus is related to poor residual beta cell function. Childhood Diabetes in Finland Study Group. Arch Dis Child 1996;75:410-5.

35. Guttmann A, Shipman SA, Lam K, et al. Primary care physician supply and children's health care use, access, and outcomes: findings from Canada. Pediatrics 2010;125:1119-26.

36. Rosenbauer J, Icks A, Giani G. Clinical characteristics and predictors of severe ketoacidosis at onset of type 1 diabetes mellitus in children in a North RhineWestphalian region, Germany. J Pediatr Endocrinol Metab 2002;15:1137-45.

37. Icks A, Rosenbauer J, Strassburger K, et al. Persistent social disparities in the risk of hospital admission of paediatric diabetic patients in Germany - prospective data from 1277 diabetic children and adolescents. Diabet Med 2007;24:440-2.

38. Guttmann ALK, Schultz S, Jaakkimainen L. Primary care for children. Toronto: Institute for Clinical Evaluative Sciences; 2006.

39. Gill PJ, Saunders N, Gandhi S, et al. Emergency department as a first contact for mental health problems in children and youth. J Am Acad Child Adolesc Psychiatry 2017;56:475-82.e4.

40. Nombre et coût des services médicaux selon le type de service, le mode de rémunération et la région sociosanitaire du dispensateur, Québec. Québec: Régie de l'assurance maladie du Québec; 2004.
Competing interests: Laurent Legault has served on advisory boards for Medtronic and Lilly; has received grants for unrelated research from Merck, Sanofi and AstraZeneca; and holds a share of intellectual property not related to this work. No other competing interests were declared.

This article has been peer reviewed.

Affiliations: Department of Pediatrics (Nakhla, Legault, Li), The Montreal Children's Hospital, McGill University; Research Institute of the McGill University Health Centre (Nakhla, Rahme, Legault, Li), Montréal, Que.; Institut national de santé publique du Québec (Simard, Larocque), Québec, Que.

Contributors: Meranda Nakhla conceptualized and designed the study, provided oversight of the analysis, interpreted the data and drafted the initial manuscript. Elham Rahme, Isabelle Larocque and Patricia Li conceptualized and designed the study, provided oversight of the analysis, interpreted the data, and critically reviewed and revised the manuscript. Marc Simard contributed to study conception and design, carried out the analy- sis, contributed to interpretation of the data, and critically reviewed and revised the manuscript. Laurent Legault contributed to study conception and design, provided oversight of the analysis, interpreted the data, and critically reviewed and revised the manuscript. All of the authors gave final approval of the version to be published and agreed to be accountable for all aspects of the work.

Funding: Meranda Nakhla and Patricia Li were funded by Chercheurboursier clinicien Junior 1 awards from the Fonds de recherche du Québec - Santé (FRQS) and the Ministère de la Santé et des Services sociaux du Québec. Patricia Li was also funded by a New Investigator Salary Award from the Canadian Institutes of Health Research. This research was also supported by the Research Institute of the McGill University Health Centre. The funders played no role in conduct or management of the study; collection, analysis or interpretation of data; or preparation of the manuscript.

Accepted: Nov. 11, 2017

Correspondence to: Meranda Nakhla, meranda.nakhla@mcgill.ca 